\title{
Avaliação: um desafio no processo de ensino-aprendizagem na educação - revisão de literatura
}

Evaluation: a challenge in the teaching-learning process in education - literature review

Evaluación: un desafío en el proceso de enseñanza-aprendizaje en la educación - revisión de literatura

\section{Leydiane da Conceição Gomes Ferreira Martins ${ }^{1 *}$, Luana Frigulha Guisso².}

\section{RESUMO}

Objetivo: Revisar na literatura científica diferentes concepções à novas formas de mensuração e classificação de resultados, com práticas avaliativas voltadas ao desenvolvimento do educando e às suas inúmeras capacidades e habilidades, em que as dificuldades sejam consideradas como início de um processo de ensino-aprendizagem. Métodos: Apresentar estudo de cunho bibliográfico, de como a avaliação da aprendizagem é vivenciada no contexto escolar, propondo nova concepção de avaliação da mesma. Utilizouse livros e materiais como base teórica para responder tais indagações. Resultados: Mostrar que o ato de avaliar é indispensável ao processo de ensino-aprendizagem, especialmente, considerando que a avaliação tende a subsidiar a construção desse processo. Nota-se a necessidade de entender e discutir mais sobre a avaliação da aprendizagem no contexto escolar, por professores e alunos, sobre a definição de conceitos, teoricamente, fundamentados. Considerações finais: O conceito de avaliação da aprendizagem, embora indefinido, apresenta interpretações que divergem da real função dela no processo de ensino-aprendizagem. Muitos professores, alunos e profissionais de educação ainda não compreendem o real significado da avaliação, atribuindo a ela valor punitivo, de ameaça, voltado exclusivamente para uma classificação, sem debater mais, e, assim, contribuir de fato para a melhoria do processo de ensino-aprendizagem.

Palavras-chaves: Avaliação, Ensino-aprendizagem, Práticas avaliativas.

\begin{abstract}
Objective: Review in the scientific literature different conceptions to the new forms of measurement and classification of results, based on evaluative practices aimed at the development of the student and his numerous capabilities and abilities, in which difficulties are considered as beginning of a teaching-learning process. Methods: Present a bibliographic study of how the evaluation of learning is experienced in the school context, proposing a new conception of the same as books and materials as a theoretical basis for answering questions. Results: The act of evaluating is indispensable to the teaching-learning process, especially considering that the evaluation tends to subsidize the construction of this process. It is noted the need to understand and give more about the evaluation of learning, in the school context by teachers and students, on the definition of concepts theoretically base. Final Considerations: The concept of learner's avaliation, although undefined presents interpretations that diverge from the real function of the learner in the learning process. Many teachers, students, and educational professionals still do not understand the significance of evaluation, attributing to it punitive, threatening value, aimed exclusively at classification, without debating more, and thus actually contributing to the improvement of a teaching-learning process.
\end{abstract}

Keywords: Evaluation. Teaching-learning. Evaluation practices.

${ }^{1}$ Prefeitura Municipal de Presidente Kennedy-ES. * E-mail: leydianecgfm@ @otmail.com
2Faculdade Vale do Cricaré, São Mateus-ES.

SUBMETIDO EM: 1/2019

ACEITO EM: 2/2019

PUBLICADO EM: 5/2019

REAS/EJCH | Vol.Sup.24 | e379 | DOI: https://doi.org/10.25248/reas.e379.2019 Página 1 de 6 


\section{RESUMEN}

Objetivo: Revisar en la literatura científica diferentes concepciones sobre las nuevas formas de medición y clasificación de resultados, con las prácticas evaluativas dirigidas al desarrollo del educando ya las innumerables capacidades y habilidades, en que las dificultades sean consideradas como el inicio de un proceso de enseñanza-aprendizaje. Métodos: Presentar un estudio de cuño bibliográfico, de cómo la evaluación del aprendizaje es vivenciada en el contexto escolar, proponiendo una nueva concepción de a varianza de la misma. Utilicen libros y materiales como base teórica para responder tales indagaciones. Resultados: Mo que el acto de evaluar es indispensable al proceso de enseñanza-aprendizaje subsidiar la construcción de ese proceso. Se observa la necesidad de entender y dis-más sobre la evaluación del aprendizaje, en el contexto escolar, por profesores y alumnos, sobre la definición de conceptos teóricamente fundamentados. Conclusiones Finales: El concepto de evaluación del aprendizaje, es algo indefinido, presenta interpretaciones que difieren de la función real de ella en el proceso. Muchos profesores, alumnos y profesionales de la educación, todavía no comprenden el real significado de la evaluación, atribuyéndole el valor de un instrumento punitivo, de amenaza, volcado exclusivamente a una clasificación, sin debatir más, y así contribuir de hecho a la mejora del proceso de enseñanza-aprendizaje.

Palabras claves: Evaluación. Enseñanza y el aprendizaje. Prácticas evaluativas.

\section{INTRODUÇÃO}

Por muito tempo a avaliação da aprendizagem significou meramente a análise do "erro" do educando. Hoje, embora ainda com essa concepção, a avaliação, no âmbito educacional, tem sido utilizada a serviço da aprendizagem e na verificação da qualidade do ensino no país. A avaliação, tem como objetivo um ensinoaprendizagem significativo, o que quer dizer, avaliar de forma expressiva é desenvolver práticas educativas, levando em consideração os conhecimentos prévios dos alunos; diagnosticando as defasagens metodológicas, tanto das práticas avaliativas, quanto do sistema de ensino, com conteúdo que auxilie a aprendizagem do aluno e não apenas a memorização (LUCKESI CC, 2011).

A avaliação, precisa ser processual e contínua. O aluno precisa ser avaliado durante todo o ano letivo, em todas as suas potencialidades, permitindo diagnosticar os avanços e as dificuldades no cotidiano da prática pedagógica, e não ao final de cada trimestre. É realizada por meio de análise, síntese e pesquisas do conhecimento construído pelo aluno. A partir dos resultados, permite reformular novos caminhos e reorganizar novas práticas educativas para que o aluno consiga reestruturar a própria construção do conhecimento (LUCKESI CC, 2011).

Todavia, tornou-se válido pensar na seguinte problemática: O que é possível acreditar e fazer para mudar, transformar conceitos, romper paradigmas, reconstruir padrões alicerçados como corretos e eficientes, repensando novas práticas educativas para o ensino-aprendizagem do aluno?

Desse modo, como objetivo, é importantíssimo perceber a necessidade de buscar formas de mensuração e classificação de resultados, com práticas avaliativas voltadas ao desenvolvimento do educando e às suas inúmeras capacidades e habilidades, em que as dificuldades sejam consideradas como início de um processo de aprendizagem.

O objetivo deste estudo foi revisar na literatura científica diferentes concepções à novas formas de mensuração e classificação de resultados, com práticas avaliativas voltadas ao desenvolvimento do educando e às suas inúmeras capacidades e habilidades, em que as dificuldades sejam consideradas como início de um processo de ensino-aprendizagem.

\section{Avaliação da aprendizagem: aportes teóricos conceituais}

De acordo com o histórico da legislação educacional brasileira, o conceito da avaliação da aprendizagem, é um termo que passou a ser utilizado recentemente. Até então, se abordava "verificação do aproveitamento ou rendimento escolar", e se tratando da aprendizagem, sequer era mencionada, tão pouco concebida como 
um processo em que o educando fazia parte. No entanto, com a criação das Diretrizes e Bases da Educação (LDB), em 1961, é que ficou assegurada a exclusividade da avaliação e a formulação de questões e julgamento ao professor (BRASIL, 1961). Contudo analisando o Parecer oㅜ 102, de junho de 1962 (BRASIL, 1962), do Conselho Federal de Educação (CFE), com a proposta de uma interpretação em relação ao artigo 39 da Lei de Diretrizes e Bases (LDB), documento este, que propõe que a avaliação não seja realizada apenas com a aplicação de exames e provas isoladamente, mas que a aprendizagem do aluno seja verificada e observada, por meio de um processo, ao longo de todo o ano letivo (BRASIL, 1962).

Originado do latim, verificare, se dá o termo verificar, que significa averiguar, certificar-se, confirmar, examinar, analisar o teor da verdade de alguma coisa, uma vez confirmada a veracidade o processo da verificação se conclui. $O$ termo avaliar, também de origem do latim, a-valere, que significa determinar ou atribuir o valor de reconhecer a grandeza, a força ou a intensidade, apreciar-se, calcular e julgar, avaliar é um processo de constatação e ação após o resultado (DICIONÁRIO ONLINE DA LINGUA PORTUGUESA, 2018).

Sobre essa perspectiva, Luckesi CC (2011) considera que os significados da verificação e a avaliação são bem diferentes, pois a segunda requer uma continuidade no processo, não podendo ser dado o resultado como algo acabado ou concluído. Contudo, percebe-se que as escolas, têm mantido a utilização do ato de verificar o rendimento escolar do educando (LUCKESI CC, 2011).

Aprender a avaliar, é aprender os conceitos teóricos do que é avaliação. Não bastante, é preciso mais do que isso, é preciso exercer no cotidiano da prática escolar, atos e atitudes (LUCKESI CC, 2011). Quanto a isso, o pesquisador posiciona a necessidade de uma reflexão constante, em relação à prática avaliativa docente, num processo permanente de questionamento.

De acordo com Hoffmann J (2005), deve-se lembrar que questionar e refletir, são ações que precisam se perpetuar na postura do professor, refletindo a realidade dele e a do educando, na construção significativa do conhecimento. Isso porque, avaliar vai além do ato de aprender, está associado ao ato de ensinar, pois o professor não leva em consideração as próprias práticas e habilidades enquanto aprende e ensina. Já aluno, por sua vez, não compreende que a aprendizagem dele precisa ser um processo em construção do conhecimento, e se detém apenas às formas como o ensino é transmitido em sala de aula (HOFFMANN J, 2005).

Segundo Libâneo JC (2004), a avaliação possibilita também examinar o trabalho do professor, esse processo de resultados permite fazer inferências nas ações do ensino, onde o professor observará como está sendo realizado a sua prática avaliativa, é na avaliação que se percebe suas qualidades. Com tudo, é necessário por parte do professor flexibilidade, força de vontade, adaptação e criatividade aliadas à sua prática docente e avaliativa (HADJI CA, 2001).

Assim, Vasconcellos (2002), enfatiza que esse processo avaliativo vem orientar o professor e o aluno, quanto ao seu trabalho, num objetivo de crescimento, se redirecionando a aprendizagem do aluno. $O$ aluno é obrigado a refletir através do processo avaliativo, se conscientizando do seu próprio estágio de desempenho (RAMOS RY, 2000).

A fim de que haja uma relação ensino-aprendizagem no processo avaliativo, é preciso existir um feedback, integrando professor e aluno, sendo assim, o desenvolvimento da aprendizagem se torna muito mais propicio a acontecer; onde a troca de conhecimento tenha um retorno recíproco entre as partes envolvidas. (HAYDT, 1988).

Na concepção de Luckesi CC (2011) a avaliação da aprendizagem precisa cumprir seu verdadeiro papel, que é o de auxiliar o crescimento do aluno. O autor enfatiza que o professor deve deixar de utilizar a avaliação de forma autoritária, e se detenha à construção da aprendizagem do educando. Luckesi CC (2000), afirma que a avaliação é um ato amoroso, por isso, a importância do processo de ensino-aprendizagem no contexto escolar. Para a relação professor e aluno funcionar bem, ambos precisam assumir uma postura de reciprocidade, e, este ato reflete no processo avaliativo da aprendizagem (LUCKESI CC, 2000). 
Contudo, as práticas avaliativas estão arraigadas ao ato de examinar, numa visão de que avaliar significa o mesmo que notas, exames e resultados satisfatórios e não satisfatórios. $O$ ato de examinar, não se restringe ao fato que todos aprendam com qualidade, possuindo uma função classificatória. Diferentemente disso, o ato de avaliar, tem a função investigativa, considera a qualidade da aprendizagem e do ensino e prossegue com uma intervenção com a finalidade de mudanças e melhoria dos resultados (LUCKESI, 2011).

Portanto, é válido afirmar que o ato de avaliar, se acentua numa investigação de possíveis diagnósticos, na tentativa de solucionar as dificuldades, e, esse processo requer coletas de dados para verificar os motivos de o educando não ter aprendido, considerando todas as variáveis possíveis e não colocando só a responsabilidade do fracasso no aluno. Assim, pondera ainda que é preciso que a escola passe do ato de examinar para o ato de avaliar, num processo de metanoia, isto é, mudanças de conceitos e modos de agir que não mais contribuem com o prosseguir das práticas profissionais (LUCKESI CC, 2011).

Diante desse cenário, vale destacar a importância de romper com conceitos e práticas que ao longo dos anos fizeram da avaliação um processo sistematizado e classificatório, e se assumir novas apreciações sim, mas que sejam fundamentadas no agir das práticas avaliativas do cotidiano escolar.

\section{A avaliação e o processo de ensino-aprendizagem no cotidiano escolar}

O processo de ensino-aprendizagem no Brasil, por décadas define uma relação, pela qual vêm demonstrar a atuação da escola, em que o professor é o instrumento de ensino e o aluno absorve esse conhecimento. Assim, é função da escola certificar que o ensino e a aprendizagem aconteçam e que esse conhecimento sistematizado seja recebido na sociedade, por meio do mercado do trabalho (SAVIANI D, 2000).

Mediante a concepção do autor esse processo é fragmentado. Foi necessária uma compartimentação das disciplinas para que houvesse uma especialização dos profissionais para atender a sociedade industrial, e, assim, facilitar a aquisição do conhecimento. Atualmente, essa separação se estende, em geral, ao contexto escolar, uma vez que tanto o ensino quanto as escolas são classificados em públicos e particulares. A avaliação da aprendizagem é feita por meio do rendimento escolar e de notas ou médias, classificando os alunos, mantendo uma separação entre o ensino e a aprendizagem (SAVIANI D, 2000).

A sociedade capitalista exige do indivíduo uma formação que esteja sempre à frente da exigência do mercado de trabalho o colocando num teste de aprovação/reprovação. Essa cultura de avaliação já está arraigada no processo de ensino-aprendizagem que é reproduzido na realidade das escolas. A escola não perpetua a sua função, à medida em que não cumpre com o seu papel de transformador social do cidadão. Ela trabalha com a finalidade de conservação e reprodução da sociedade (LUCKESI CC, 2011).

Sobre a forma como a avaliação tem sido utilizada no desenvolvimento do processo de ensinoaprendizagem, o autor Luckesi (2011) evidencia que a avaliação da aprendizagem no cotidiano escolar está distanciada da relação professor-aluno. A relação entre ambos, precisa estar fundamentada na confiança, no respeito mútuo, no diálogo e na cumplicidade. Assim, para ele, mesmo que surjam dificuldades na aquisição da aprendizagem, e seja necessária a reavaliação, essa relação não ficará comprometida (LUCKESI CC, 2011).

Essa forma de avaliação, faz com que o professor assuma um papel de detentor do saber, aquele preparado para o ensino, então atribuída a ele a função de avaliar seus alunos pelas notas e não a partir de um ensino e aprendizagem significativos. Há uma relação de poder, num processo em que deveria haver trocas de saberes (LUCKESI CC, 2011).

Contextualizando essa troca de conhecimento, ensinar é mais. Vai além de transferir conhecimentos e conteúdos. Ensinar não existe sem aprender, em que também o aprender não acontece sem o ensinar; e, historicamente, esse processo vem se concretizando na educação e na vida (FREIRE P, 2011).

O escritor e filósofo ressalta que o processo de ensino-aprendizagem é indissociável, pois ambos, professor e aluno, precisam se colocar um no lugar do outro. No entanto, o professor tem estabelecido uma relação de poder, já que ele usa de forma autoritária a avaliação, como mecanismo disciplinador de condutas 
sociais, de forma ameaçadora (LUCKESI CC, 2011). Logo, nota-se que o aluno passa a ser reprimido por suas atitudes ou comportamentos por meio da aplicação e dos resultados de testes e provas.

Os PCN's abordam o tema avaliação da aprendizagem numa concepção de que ela é parte de um processo de ensino-aprendizagem, não se restringindo ao julgamento de um fracasso escolar do aluno, mas, oferecendo subsídio de uma intervenção pedagógica, orientando a reflexão da prática docente e as possibilidades do educando, e, ainda, definindo para a escola, as prioridades e as ações que mais demandam soluções (BRASIL, 1997). Diante das discussões e dos pensamentos dos autores, deve-se ponderar aqui que esse processo de ensino-aprendizagem, considera que tais personagens desse processo, professor e aluno, precisam exercer a curiosidade e o diálogo. O professor precisa ter a curiosidade de tudo que envolve seu aluno, permitindo uma busca de informações, estimulando o diálogo e a troca de experiências. É importante, escutar os alunos, as dificuldades, os sonhos, os anseios deles, aprendendo, então, a ouvi-los (FREIRE P, 2011).

\section{DISCUSSÃO}

Atualmente, se fazem necessárias mudanças que contribuam para a construção de uma educação de qualidade. Tal cenário em que remete está a educação, que exige transformação e novas práticas educativas no contexto escolar. Assim, tornou-se possível entender que é necessário que o professor assuma uma curiosidade, uma vontade, que emana de si próprio em busca de novos conhecimentos, numa interação dialógica entre o ensinar e o aprender. Isso, porque ensinar exige pesquisa e o professor, na prática docente, precisa sempre pesquisar para conhecer o que ainda não sabe (FREIRE P, 2011).

Sendo assim, Hoffman J (2005), considera que a avaliação é algo indefinido. De tal modo, tornou-se possível afirmar que conhecer e entender o que é e como precisa ser aplicada a avaliação no contexto escolar é fundamental ao professor, caso contrário, a avaliação continuará sendo usada de forma classificatória, não auxiliando nos resultados almejados, como uma aprendizagem significativa para o aluno.

Igualmente, notou-se que a avaliação utilizada em sala de aula, sem se preocupar se é a melhor forma e se estão assumindo uma função comprometida com a aprendizagem do aluno, isso parte pelos professores, pela gestão escolar ou pelo sistema educacional. Com isso, há de se pensar em novas perspectivas, é necessária uma avaliação que compreenda os estágios de aprendizagem do aluno, seus avanços e defasagens (LUCKESI CC, 2011).

Observa-se que o professor é quem precisa perceber esses momentos, agir e retroceder de acordo com as percepções em relação ao seu aluno. Isso mostra a necessidade de mudanças, além dessa proposta de avaliação formativa, mudanças no sistema, na educação, na escola, partindo de uma avaliação qualitativa que, de fato, sobreponha os aspectos quantitativos dos testes e exames que são consolidados no cotidiano da sala de aula (PERRENOUD P ,1999).

Sendo assim, Rabelo (1998) considera que o educador, principalmente, tem a responsabilidade, por meio das práticas avaliativas mudar o contexto do cotidiano escolar, transpor de uma avaliação com a função classificatória, para a função diagnóstica, contínua e processual, na intenção de aprendizagem significativa com promoção qualitativa (RABELO EH, 1998). Compreende-se que o ato de avaliar é algo indispensável ao processo de ensino-aprendizagem, especialmente, considerando que a avaliação assume a característica de subsidiar a construção desse processo. Nota-se, portanto, a necessidade de mudanças de postura e práticas avaliativas que assumam o diagnóstico como começo, meio e fim no processo avaliativo utilizados na educação como um todo (LUCKESI CC, 2011).

\section{CONSIDERAÇÕES FINAIS}

Assim, concluiu-se que o conceito em relação a avaliação da aprendizagem, é algo indefinido, já que os sujeitos apresentaram interpretações que divergem, em sua maioria, da real função da avaliação no processo de ensino-aprendizagem. A partir desse estudo, percebeu-se que muitos professores, alunos, coordenadores 
pedagógicos e outros profissionais de educação, ainda não compreendem o real significado da avaliação. Com isso, acabam atribuindo a ela o valor de um instrumento punitivo, de ameaça, voltado exclusivamente para uma classificação, sendo que a real necessidade é a de debater, conversar mais sobre o conceito de avaliação, pesquisar e aprender cada vez mais, e, assim, contribuir de fato para a melhoria do processo de ensino-aprendizagem. É necessária uma avaliação de qualidade, pautada nos verdadeiros e significativos objetivos, caso contrário, como saber o quanto o aluno avançou na aprendizagem ou está em defasagem em determinados conteúdos. Por fim, compreendeu-se aqui que o professor é o protagonista principal desse processo, independente da imposição do sistema escolar, das diversas formas de avaliar e dos inúmeros instrumentos avaliativos escolhidos. A concepção, o planejamento, a prática e as escolhas desse profissional é que tornarão a avaliação significativa para o processo de ensino-aprendizagem na construção do conhecimento do aluno.

\section{REFERÊNCIAS}

1. AVERIGUAR. In: DICIO, Dicionário Online de Português. Porto: 7Graus, 2018. Disponível em: https://www.dicio.com.br/averiguar/. Acesso em: 27/04/2019.

2. BRASIL. Conselho Federal de Educação. Parecer do CFE no 102. 09 de jun. 1962. Disponível em: http://www.bvanisioteixeira.ufba.br/artigos/apuracao.html. Acesso em: 01 set. 2018.

3. BRASIL. Lei $\mathrm{n}^{0}$ 4.024. Fixa as Diretrizes e Bases da Educação. D.O.U., 20 dez. 1961. Disponível em:http://www2.camara.leg.br/legin/fed/lei/1960-1969/lei-4024-20-dezembro-1961-353722-publicacaooriginal-1pl.html. Acesso em: 01 set. 2018.

4. BRASIL. Parâmetros Curriculares Nacionais. Brasília: Ministério da Educação e do Deporto: Secretaria da Educação Fundamental, 1997.

5. FREIRE P. Pedagogia da autonomia: Saberes necessários à prática educativa. 43á.ed. São Paulo: Paz e Terra, 2011.

6. HADJI CA. Avaliação desmistificada. Porto Alegre: Artmed, 2001

7. HAYDT RCC. Avaliação do processo ensino-aprendizagem. São Paulo: Ática, 1988

8. HOFFMANN J. Avaliação - Mito e desafio: uma perspectiva construtivista. Porto Alegre: Mediação, 2005.

9. LIBÂNEO JC. Organização e gestão da escola: teoria e prática/José Carlos Libaneo. 5. ed. revista ampliada Goiânia: Editora Alternativa, 2004.

10. LUCKESI CC. Avaliação da aprendizagem escolar: estudos e proposições. 22a ed. São Paulo: Cortez, 2011

11. LUCKESI CC. O que é mesmo o ato de avaliar a aprendizagem? Pátio, Rio Grande do Sul, n. 12, p. 6-11, fev/mar. 2000.

12. PERRENOUD P. Avaliação da excelência à regulação das aprendizagens: entre duas lógicas. Porto Alegre: Artes Médicas Sul, 1999. SANT'ANA, Ilza Martins. Por que avaliar? Como avaliar? Critérios e instrumentos, 9 edição. Petrópolis. Editora Vozes: 1999.

13. RABELO EH. Avaliação: novos tempos e novas práticas. Petrópolis, RJ: Vozes, 1998.

14. RAMOS RY. Avaliar conforme um currículo integrado com temas transversais. Pátio, Rio Grande do Sul, n.12, p. 12-16, fev/mar. 2000.

15. SAVIANI D. Pedagogia histórico-crítica: primeiras aproximações. Campinas: Autores Associados, 2000. 